\title{
ICTs and community and suggestions for further research in Scotland
}

\author{
Anna Malina \\ University of Dundee $<$ anna@annamalina.co.uk $>$ \\ Ian Ball \\ University of Dundee $<$ w.i.ball@Dundee.ac.uk $>$
}

\begin{abstract}
Since the early 1990s, strategies for the Information Society have affected the UK's social and economic policies and the emergence of information and communication technologies (ICTs) in local communities. Contemporary ICTs are suited to handling complex processes so affecting society's structures and the ways in which people participate in social, cultural, political and economic life. The technology has also been appropriated by grassroots and community development movements for use in community based systems. Community networks can be used by many different groups and can operate from any venue in the community, and they can be adapted for all kinds of purposes. The most common suggestion, however, is that community networks provide services to enhance communities, in particular disadvantaged geographic communities. In addition, many countries have set strategies to close the 'digital divide,' and have funded locally based technology projects in attempts to achieve universal access and include communities and groups deemed to be in danger of exclusion from the perceived advantages offered by contemporary technology.

This paper reviews research that explores ways in which new technologies are significant for aspects of community and human interaction. The strategies and plans to install information and communication technologies (ICTs) in communities throughout Scotland are briefly summarized. Short case studies of two different programs in Scotland are considered: the Scottish Executive funded program 'Digital Communities' and the EU funded project DEMOS. This paper then highlights aspects of sustainability, i.e. the maintenance of community enabling ICT efforts over the longer term. In the fifth and last section recommendations for future research of ICT and community are offered.
\end{abstract}

\section{ICT and community: Overview of research}

Some commentators have provided early overviews of the technological and social issues surrounding ICTs and community (e.g. Schuler \& Namioka, 1993), and some have outlined the practical issues and activities which potential community networkers might consider (e.g. Bajjaly, 1999; Cohill \& Kavanaugh, 2000). Supportive commentators attempt to increase awareness of the value of community networks to the community (e.g. Pantry, 1999). In addition, textbooks offer guidance in shaping community-building processes and building community assets (e.g. Kretzmann \& McKnight, 1993). Some scholars have begun to explore the relationships and interrelationships between real and virtual communities, in particular looking at the development and use of community networks, (e.g. Schuler 1994, Cohill \& Kavanaugh 1997; Schmitz 1997; Silver 1996, 1999, 2000). Underpinning much of this literature is the notion that with appropriate values and guidance, investment in local networks will provide opportunities to build social capital and so bring greater opportunities to local neighbourhoods. 
Largely unsubstantiated claims have been made in relation to the worth of new technology. Optimistic commentators have claimed that ICTs increase social capital, while pessimists suggest technology decreases capital and undermines social relationships in the off-line world.

As an alternative to conjecture and anecdotal evidence, Quan-Haase, Wellman with Witte \& Hampton (2002) investigate how the use of the Internet and electronic interaction in Canada affects social capital. The important goal here is to question "if the Internet increases, decreases, or supplements social capital" (p.293). The authors point out that local offline community is often supplemented by on-line interaction. The overall suggestion is that the internet has the potential to help people, particularly young people, increase their social contacts.

A further argument made by Quan-Haase et al (2002) is that technology provides opportunity to seek better information, e.g. political and organisational information, in an affordable and convenient way. However, those disinterested in public affairs are not likely to suddenly become interested as a result of the Internet. Behaviour will not automatically alter as a result of using technology alone. The authors conclude that levels of Internet involvement will not radically affect civic engagement and increase a sense of community, and will not necessarily be associated with either more or less Internet involvement.

Keith Hampton, in his project on e-Neighbors, addresses concerns about the effects of the internet on family and family life. His study examines the current relationship between Internet use and the size and composition of people's social networks; and explores the potential for new ICTs to expand social networks, social capital and community involvement at neighbourhood level.

A report on this project in Spectrum (Spring, 2004), indicates that Internet services were provided to adult residents of three neighbourhoods. Neighbourhood email was found to be the most widely used service. While advice on home repair was a key topic on email for almost a year, attention was subsequently drawn to local politics and local issues, and participants became active in changing aspects of the neighbourhood.

Social network analysis is focused on uncovering the patterning of people's interaction. Hampton \& Wellman (2002) suggest that ICTs provide new opportunities for developing new social networks, and relationships, and inter-relationships can be strengthened through active community interaction.

The implications of electronic networking have also been described elsewhere. Castells (1996), for example, offers a theory of the information age, in which he claims a new epoch has just begun, producing a more effective, flexible, yet harder form of capitalism (Castells, 1996). In The Rise of the Network Society, Castells (1996) argues "as a historical trend, dominant functions and processes in the Information Age are increasingly organised around networks" (p. 469).

In Castell's opinion, exclusion from the network is to be wholly without social, economic and political power. He also warns that one network can subsume another which is less powerful. This, he suggests, is what wholly modifies all existing structures of "production, experience, power, and culture" (Castells, 1996, p. 469).

The concept of electronic networking to support social and economic life has been central in developing local technology infrastructure and electronic community networks. Many governments began to fear exclusion from the network, predicating a spate of funding to support the development of ICTs in local communities.

In a previous publication (Malina 2002), I discuss the development and perceived significance of the Craigmillar Community Information Service (CCIS), a technology supported community network set up to support social and economic regeneration of Craigmillar, a deprived area in Edinburgh, Scotland.

Three theoretical frameworks were developed: digital democracy, urban entrepreneurialism and benevolent capitalism. These perspectives were helpful in critically analysing the concept of community networking and its associations with civic usefulness and restitution of community in Craigmillar.

With reference to empirical data, the research indicates that while there was an assumption of public worth and residents in Craigmillar were not prevented from using the system, there was very little public access and little involvement of local people on electronic forums in the early years, i.e. between 1994 2000. 
However, during this period, the professional aid community were provided with training and were encouraged and enabled to use the system. Despite support, however, analysis of data suggests that on-line use by aid groups was extremely poor. Important new information was not posted on-line and interaction was infrequent and lacked vitality. A great deal of rivalry and jealousy existed between individuals and groups in the area and distrust in the real world seemed to affect use of the on-line forums developed by CCIS. A deeply embedded climate of suspicion might partially be attributed to the need for the large numbers of aid groups in the area to compete against one another for finite amounts of urban aid and local council funding.

The study highlights similarities and differences in the perceptions of respondents, i.e. sponsors (the local city council), developers (community practitioners), and users (a large grouping consisting of local voluntary organisations and aid groups). For example, while sponsors and developers believed the community network should be community owned, users indicated there were no feelings of community ownership.

Moreover, while sponsors and developers did not think CCIS should provide public access, perceiving instead a need to engage the residential community via existing representative groups, aid group users believed strongly that CCIS should provide local access and champion community participation and use. Aid groups in general believed local residents should own, develop and freely participate in and use the local network.

The research also suggests that the local council, developers of CCIS, and representatives of the aid community involved on the Management Committee, tended to monopolise key decisions in the local area. In addition, problems were perceived in information sharing. Sponsors and developers highlighted the myth that real information was being shared, both in the real world and on the virtual forums operated by CCIS. Users also commented on the inability of power holders to relinquish power and share real information. There was some agreement between respondents that sharing real information would be necessary before open interaction could be achieved. The belief commonly held by all groups was that without motivation to share information openly, both off-line and on-line, no one was likely to be empowered significantly by technology of any type.

To survive, CCIS had to adapt and undergo several design changes over its life-time, moving between profit-making and non-profit-making activities. During the last few years of operation, the community network functioned primarily as a local learning centre, offering Internet access and technology training to the local residential community. Electronic forums were re-designed in the late period of CCIS's life, in an attempt to encourage local resident participation. However, in 2003, funding was withdrawn and the project ended.

Experiments in developing ICT at community level are now being placed under the heading of Community Informatics (CI). Gurstein (2003) views CI as:

[...]the design and application of information and communications technologies to enable community processes and the achievement of community objectives, such as overcoming "digital divides", "wiring (and ensuring connectivity for) the farthest reaches of a far-flung nation", creating on-line "communities of interest" and "communities of practice", and others. Even more important, Community Informatics involves working to find ways of making the enormous opportunities of Internet connectivity of real value to various communities --- local and virtual, in achieving their economic, social and cultural objectives. Community Informatics traditionally has been applied to "geo-physical" or "local" communities, which address the needs and interests of particular (local) geographical areas. ( $(11)$

Keeble \& Loader (2001) view CI as a "multi-disciplinary field for the investigation and development of the social and cultural factors shaping the development and diffusion of new ICTs and their effects on community development, regeneration and sustainability." The authors suggest this may be done by analysing the relationship between new technology and changing social relationships; and also by assessing practical projects that explore how technology affects economic regeneration and democratic participation.

\section{Summary of plans to install ICT in Scotland's communities}


In Scotland during the 1990s, Priority Partnership Areas (PPAs) highlighted needs in the most deprived Scottish communities. As PPAs began to evolve into new Social Inclusion Partnerships (SIPs), ${ }^{1}$ ICTs were being recognised as useful tools to build social capital, support community development practice and increase civic interaction and democratic participation. Resnick (2001) indicates that social capital may be derived from resources such as: shared knowledge and values, well-defined roles and established norms of behaviour, a feeling of responsibility and obligation to others, good social relations and shared trust, supported by strong communication structures and free flow interaction.

A growing body of literature suggests that social capital is affected by better health, better education, lower crime, economic development and good government. The use of locally based ICTs in deprived communities and areas in crisis began to filter into community development practice and efforts to accumulate social capital in the UK during the 1990s (see Malina, 2001, 2002).

The UK government also feared that many citizens were unprepared for the Information Society, and a range of policies and directives emerged to tackle the 'digital divide,' particularly in communities suffering socio-economic problems. Government funding since 1998 was designed to address the perceived problem of digital exclusion. The development of skills to use the technology and access to IT centres became a central focus.

Throughout 1999, the development of IT Learning Centres increased and emphasis was placed on ensuring that people in deprived areas were able to access technology and acquire the key IT skills suitable to the demands of an Information Society.

Malina \& Macintosh (2004) outline developments in Scotland in some depth; however, it is worth summarising strategies briefly. The Digital Scotland Task Force (2000) report suggests that ICT projects in local communities should be given priority in social inclusion programmes. In addition, the Scottish Executive, i.e. the devolved government of Scotland, is committed to closing the 'digital divide,' aiming to support universal access to the Internet by 2005 .

'Digital Scotland,' a Scottish Executive initiative, claims to be working towards maximum social and economic advantage from the development of ICTs. The Executive's Digital Inclusion strategy set plans for the use of advanced networked technologies in education and life-long learning. By early 2000, PCs had been installed in various community centres and halls in Scotland. Voluntary sector content through a web portal $^{2}$ was developed to close the perceived digital divide and provide a single gateway to Scotland's voluntary sector.

From 2000 onwards, Scottish Executive policies have continued to work towards widespread public access. A three-year 'Digital Champions programme' has supported the goal of inclusive ICT provision in Social Inclusion Partnerships (SIPs) areas in Scotland. The Digital Inclusion Team of seven 'digital champions' operates from the Local Enterprise Company based in each local SIP area. The programme was designed to support community professionals with local knowledge in their efforts to break down barriers and encourage and include those who remained outside existing ICT provision.

Much effort has been expended in local communities, particularly in deprived neighborhoods, to help close the digital divide. However, the Digital Inclusion Audit (2004) conducted in Scotland's SIP areas points out that while $83 \%$ of centers still offered free access to the public, only $50 \%$ of facilities offered formal training classes. Moreover, a significant gap was noted between on-line activities and levels of training to support those activities.

There seems to be a question mark over the sustainability of some projects in Scotland. The Digital Inclusion Audit (2004), for example, indicates that while there has been an $8 \%$ increase in internet access since March 2003, 47 centers had been closed or no longer provided internet access.

Installing broadband at local levels has been a key policy issue in Scotland to support social and economic outcomes. Much emphasis has been placed on expanding the communications infrastructure (see

1 Areas which experience high levels of deprivation in Scotland have been designated a "SIP area." These areas benefit from extra government funding and formal partnership structures which bring together key public, private and voluntary agencies and community representatives.

2 www.workwithus.org Consulted November 2002 
Connecting Scotland: Our Broadband Future, 2001a), and addressing poverty, lack of awareness, and low skill levels (see Digital Inclusion, Connecting Scotland's People, 2001b). However, analysis of data outlined in the Digital Inclusion Audit (2004) suggests need for a more comprehensive and joined-up approach. For example, the audit found that $80 \%$ of facilities had broadband connection, however, many centers had little or no formal technical support. Moreover, while many centers provided disabled access, only half provided specialist kit for disabled people to actually access and use the technology. It appears then that use of technology and the Internet delivered by broadband is somewhat constrained by lack of technological resources for disabled users and little or no on-site technical training.

A variety of excluded groups have been identified in social and digital inclusion initiatives in Scotland. However, the Digital Inclusion Audit (2004) indicates that while women with children are generally viewed as a group at risk of exclusion, $68 \%$ of centers audited did not provide access to childcare. Moreover, public access after 6:00 p.m. and at weekends was found to be low, with only $3 \%$ of centers opening at weekends. Thus, women routinely involved in childcare and others constrained by routine daily commitments are unlikely to be able to take advantage of public access technology.

The Digital Inclusion Audit (2004) highlights the importance of ensuring that access and training efforts are complemented by other types of support relevant to the routine needs of specific groups and tailored to local context.

Closely linked to the UK Government Portal, ${ }^{3}$ the Scottish Government Portal under the brand of OpenScotland ${ }^{4}$ has begun to promote public take-up of electronic services. OpenScotland provides an umbrella framework for both the Executive's Modernizing Government and Digital Inclusion agendas. Ensuring public access to ICT at community level remains central. However, long-term sustainability of each project does not appear to have a high priority. Moreover, not much in the way of in-depth assessment of the implications of projects for local communities is yet available.

The National Grid for Learning (NGfL) has been part of a major Government initiative to connect all schools, colleges, universities and libraries to the internet by 2002. Due to the educational, cultural and political differences between Scotland and the rest of the UK, the NGfL Scotland team was appointed by the Scottish Executive Education Department in September 1999, to take the initiative forward in Scotland. Fostering community was a key objective of the NGfL Scotland Communities team, ${ }^{5}$ whose goal was to ensure the use of ICT to improve opportunity, access and quality of life for excluded groups, and to actively involve communities in worthwhile local projects.

The communities channel of NGfLScotland has worked in collaboration with the digital champions who are based in Local Enterprise Companies, to supply information, advice and assistance to all those providing support for ICTs in their community. Moreover, NGfLScotland's Connecting Communities Training Programme, ${ }^{6}$ which ran for two years until mid-2004, promoted the effective use of ICT in community learning agencies across Scotland. The programme helped to increase the use of ICT in the running and delivery of learning agency services and to develop the ICT skills of community education practitioners and other partners in community learning. However, many projects are funded in the shortterm and unlikely to be sustained beyond the funding period.

In addition to these projects, a $£ 3.2$ million initiative, the Public Internet Access Point (PIAP) Initiative, was launched in the summer of 2002, to support the idea of socially inclusive information society development at the local level. A network of Internet access points was created in provision-poor areas of Scotland to widen public access, target disadvantaged groups and raise ICT literacy.

The objective was to provide wider public access supported by a wide range of agencies in the public, private and community/voluntary sectors in venues routinely used by the public, e.g. libraries, internet cafes and SIP-funded learning centres. In addition, access was provided in the places people already go, e.g. shops, pubs, post offices, hairdressers and community centres. Computers were also made available in venues used by excluded groups such as lone parents, ethnic minorities and New Deal clients.

3 http://www.ukonline.gov.uk/ Retrieved November 2003

4 http://www.openscotland.gov.uk/ Retrieved July, 2004

5 http://www.ngflscotland.com/communities//Retrieved July, 2004

6 http://www.ngflscotland.com/communities/training/connectingcommunities/ Retrieved July 2004 
By Spring 2004, 235 PIAPs were funded across Scotland. By that time, 95 percent of the urban population and 93 percent of people in rural areas had relatively easy local access. The 'Evaluation of the Public Internet Access Point Initiative' (2004) ${ }^{7}$ examined how well the program met original objectives, how PIAPs were being used, hosts' experiences, and value of the approach. ${ }^{8}$ The report points out that 272,000 people still remain without recommended levels of public access in Scotland. Approximately three quarters of this number live in rural areas.

Currently PIAPs are supported by Scottish Executive funding, and many hosts do not earn income from providing the service. Sustainability of these centers into the future is not certain. In addition, little is known yet about how and with what implications transformations in the nature of interaction provided by public access technology actually institutes new patterns of networking in different types of communities and how these changes subsequently impact on socio-cultural, economic and political areas of daily life.

\section{Digital Communities Scotland: Promoting digital inclusion}

In England during 2001, several pilot projects were initiated by the Department for Education and Employment (DFEE) to help tackle the digital divide. A total of $£ 10$ million pounds (sterling) was awarded to seven socially excluded communities. Broadband and narrowband access was made available as well as satellite communications and digital television. In addition, community-based portals were designed to promote the use of ICT for civic use and to help people seek employment opportunities.

In early 2001, a document titled, Digital Inclusion: Connecting Scotland's people (Scottish Executive, 2001 , p. 22) outlined intention to provide $£ 4.3$ million pounds (sterling) to fund the development of ICTs to help tackle social exclusion in one urban and one rural community in Scotland. In late 2001, communities across Scotland were invited to submit first round bids to the Scottish Executive to become digital communities.

Towards the end of March 2002, the Scottish Executive selected the two winning communities. The rural community selected covered 13 of the 26 inhabited islands in the Argyle Islands archipelago, including Mull and 13 other islands.

The map illustrated in Figure 1 indicates the dispersed nature of the Argyll Island communities, which are deemed to suffer from many issues of deprivation and disadvantage, primarily caused and/or accentuated by their remote geographical isolation. Largely related to their isolation from the mainland, the islands of Argyll are categorised as 'fragile areas' by Highlands and Islands Enterprise and as 'disadvantaged areas' by the Council's Economic Development Strategy.

Figure 1. Source: Argyll and Bute Council. First Round Digital Communities Submission

7 The full report is available at: http://www.scotland.gov.uk/library5/finance/epiapi-00.asp Accessed December 2004.

8 Further information on findings is available at http://www.scotland.gov.uk/library5/finance/epiapi01.asp\#14. Accessed December 2004 


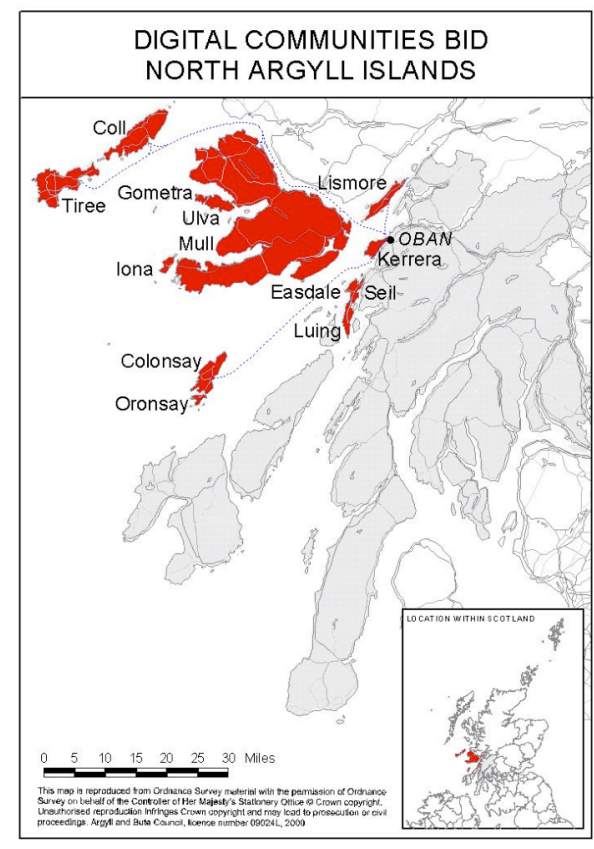

The urban community selected was Bellsmyre, West Dunbartonshire, a community suffering multiple forms of social and economic deprivation and allocated a Social Inclusion Partnership (SIP) area.

The outline proposals submitted are described in more detail elsewhere (see Malina \& MacIntosh, 2004). However, to summarize these developments, a key objective in the rural islands area proposal was to ensure all local people could profit from new opportunities to use computers and access to the Internet. For example, the intention was outlined in the North Argyll proposal to design ICTs: to help islanders communicate speedily, cheaply and more easily in regard to public services; interact with peers, telework; access health services and lifelong learning materials. Wherever possible, an additional intention was to include businesses and community groups in the island's on-line community.

The First Round Proposal produced by West Dunbartonshire Council for Bellsmyre indicated that the project would support the participation of people who were perceived to be digitally excluded.

It was hoped that a focus on leisure interests would encourage local people in Bellsmyre to engage more with new technology. Key objectives were to improve local attitudes to learning as well as attitudes to ICT, alleviate fear of technology, raise levels of educational achievement, and highlight the benefits of being connected to the web. One key aspiration was to create an ICT skilled local population, able to go on to employment. It was also hoped to establish a routine taste for further learning and training and to encourage new business start-ups.

The Digital Communities Final Report (2004) outlines findings and indicates that a total of 3,500 homes in the digital community areas received free personal computers with free internet access for a year. In addition, a web portal was established with locally developed content. The cost per household of the two year $£ 4.3$ million pound project was around $£ 1,200$. The final evaluation examined the Digital Communities initiative against Digital Inclusion Strategy objectives, as indicated in Table 1:

\begin{tabular}{|l|l|}
\hline \multicolumn{2}{|c|}{ Table 1: Themes used to evaluate digital inclusion } \\
\hline Targeting & $\begin{array}{c}\text { To assess what advantages and disadvantages arose } \\
\text { from the method of targeting the initiative broadly on a } \\
\text { geographical rather than thematic base }\end{array}$ \\
\hline Initial policy appraisal & $\begin{array}{c}\text { To provide an indication of how well the initiative met } \\
\text { its original objectives }\end{array}$ \\
\hline Process & $\begin{array}{c}\text { This is related to matching the technology to the } \\
\text { infrastructure already in place and also the introduction and }\end{array}$ \\
\hline
\end{tabular}




\begin{tabular}{|c|c|}
\hline & help participants received in the roll-out \\
\hline Training and development & $\begin{array}{l}\text { To assess whether training needs of participants were } \\
\text { met }\end{array}$ \\
\hline Impact on behavior during the pilot & $\begin{array}{l}\text { To determine what services were accessed, how } \\
\text { different parts of the community used the Internet and the } \\
\text { usefulness of the community websites }\end{array}$ \\
\hline Long term impact & $\begin{array}{l}\text { To attempt to determine how far the initiative has } \\
\text { changed behavior patterns, attitude and usage of ICT }\end{array}$ \\
\hline
\end{tabular}

A 3-wave longitudinal survey was conducted as part of the evaluation outlined (Digital Communities Final Report, 2004). Wave 1 collected data at the baseline stage prior to computer installation. This stage also noted each participant's motivation for becoming involved. Wave 2 collected data at the midway point ( 3 months after computers were delivered). The study also examined the installation process, problems experienced in using computers, and sources of help accessed. Wave 3 data was collected twelve months after computers were installed. Here, a final survey asked participants what they had gained from participating. Waves 1 and 2 were conducted by telephone, while Wave 3 was conducted face-to-face by trained interviewers. Attempts were made to interview all household members aged 12 or over to assess their views on the project.

It was noted that the data bears out the notion that different types of communities will develop different patterns of technology use. In relation to motivation for being involved (Wave 1 data), the report notes that participants in the urban community of Bellsmyre cited factors connected with learning, while participants in the remote urban communities of Argyll highlighted ability to email family and friends as well as ability to access information.

More than half of respondents in both areas used the local sites for information about local events or issues. Discussion forums in the urban community of Bellsmyre, however, were used more fully, with 33\% of users logging on to forums as opposed to only 4\% in the rural communities in Argyll. 15\% of respondents had looked at health services in Bellsmyre as opposed to 3\% in Argyll.com.

The most popular uses of computers identified in all three surveys were email and accessing the Internet - as opposed to other uses for example, playing games, writing letters and other documents, and listening to music CDs. The indication from this is that other mechanisms to facilitate Internet access, i.e. digital TVs and satellite could be considered as alternatives to PCs.

Respondents in Bellsmyre were more likely than respondents in North Argyll to report using computers for school work. The report suggests this reflects the higher proportion of households with younger families in the urban area of Bellsmyre.

Other differences in use were noted between the two communities. In the urban community, users were more likely to report using their PC for general browsing or surfing and playing or downloading music, while the remote island community were more likely to use their PC for non-grocery on-line shopping.

There was little evidence that people in either community used their PC to access public services or employment related activities. Most respondents were more interested in on-line shopping than in accessing other kinds of services, e.g. government services. Overall, the project did not seem to lead to a long-term increase in the uptake of education, training or learning opportunities. On the other hand, some participants said they would be interested in using e-learning to broaden training and education in the future.

When asked to consider personal benefits, many participants cited being able to contact people, talk to others, and/or meet new people on-line as being the main advantage. Overall, it may be argued, the ability to extend social networks was viewed as a distinct new advantage. In terms of benefits to community, interacting with others was again cited as the main advantage, with $33 \%$ of respondents in North Argyll and $4 \%$ in Bellsmyre feeling benefits from increased ability to get in touch with others in other communities more easily. 
The report suggests that future ICT and community programs need to be tailored to the needs of participants. The project acknowledges that while benefits were perceived by many respondents, there was still a significant group of people who did not take up the opportunity of ICT even with free access provided. If this group were to be digitally included in the future, their needs would have to be assessed and a different approach would be necessary.

In terms of future policy, the report suggests, community involvement is crucial, and participation should begin at the policy design stage to ensure that the needs of the community are taken into account. For the future, the report recommends that:

- $\quad$ target groups are defined;

- objectives of the intervention are clearly stated;

- the intervention is the most effective and efficient way to achieve objectives;

- outcome objectives are at the centre of policy design;

- incentives are aligned with overall objectives;

- a baseline is established;

- implementation processes take account of the current baseline position.

An interesting direction for future research would be to explore user perceptions in more depth, and assess implications for the different communities.

\section{The Demos project: Promoting wider citizen participation}

Theories of democracy assume participation of ordinary citizens, yet for many years the majority of people in representative democracies have not participated in political arenas much beyond casting their vote occasionally at elections. More recently, however, ideas about representative democracy are changing. Governments now realize they can do so more effectively when conscious of the needs and attitudes of the people. Having acknowledged public skepticism and cynicism about politics, evidenced in annually decreasing turn-out at elections and growing dissatisfaction with democratic authorities, many governments in representative democracies world-wide are attempting to develop new philosophies suited to modern society, mass communications, and more discerning life-styles.

Over the past decade or so, opinion polls and surveys have been used to garner public opinion. In the 1990 s, a number of e-democracy pilot projects emerged in local communities. Some researchers (e.g. Tsagarousianou, Tambini and Bryan, 1998) have discussed civic projects using ICT to enhance democracy, and others (e.g. Wilhelm, 2000) have examined the impacts of new ICT on the public sphere. Others still have discussed the way in which citizens have begun to use participatory monitoring and evaluation processes to secure accountability from elected officials and government agencies (e.g. Gaventa and Blauert, 1999).

Anthony Giddens (1998a; 1998b) points to a policy move in the UK to strike a better balance between economic and non-economic areas of social life. A modernising philosophy suggests everyone in the UK should rise to the civic and economic challenges of an increasingly information based society. At the same time, cooperative informatic strategies are developing practical associations between community-based ICTs, community networks and community-building activities, to improve existing structures and find better solutions to social and economic problems in excluded neighborhoods. The notion of participation is central.

Supported by the EU's Fifth Framework Program "Cities of Tomorrow and Cultural Heritage", the Demos project, ${ }^{9}$ brought together eight city governments in seven countries with research organizations across Europe, to examine aspects of citizen participation in local government. The project, which ran from $2002-2004$, was designed to examine ways to re-energize local democracy and to include citizens more fully in governance. The local projects in citizen participation, which were developed in each of the eight cities, have provided a range of learning opportunities to assess what is happening with ICT at small-scale levels. The central aim of the Demos project was to monitor innovative approaches to citizen participation

9 Official Demos web site is at: $\underline{\text { http://www.demosproject.org/webpages/aboutus.htm }}$ 
using action research methods. In Scotland, local projects involving ICT and community were developed in the cities of Aberdeen and Edinburgh.

\section{Demos - ICT projects in Aberdeen communities}

Aberdeen City Council ran a city wide Citizen's Panel for one year from February 2003 until February 2004. Having received training and regular information, a group of 1350 citizens agreed to join a panel for the City of Aberdeen. The panel routinely received questionnaires on new service proposals, how services were performing and proposed changes to service provision. Members were drawn from all areas of the city and included representatives from ethnic groups, young people, and older members of local communities. In addition, the panel drew together a partnership between public service providers including the Police, the Health Service, the Scottish Executive Housing Adviser, the Fire and Rescue Service, the local enterprise company and the Aberdeen Council of Voluntary Organizations.

A Virtual Citizens Panel website was also set up as part of the Demos Project, presenting people in Aberdeen with opportunity to use ICTs to respond to the citizen's panel questionnaires. The on-line Panel receives the same information as its real time counterpart. While members of the 'virtual' panel remain anonymous, information about age group, gender, ethnic group, and postcode of participants is recorded. This data indicates what types of groups/people are prepared to interact in this way with the council and its partners. The goal of the City Council and researchers in the Demos project is to compare real-time representative responses with virtual responses. The approach being taken in the in-depth evaluation - to be made available at a later date - is to compare and contrast data in order learn from perceived benefits and problems. Early suggestions are that each system will have benefits and drawbacks, which will be highlighted in the research data. When these are understood more fully, it is likely that on-line and off-line citizen panels will be re-designed to run alongside and complement one another.

\section{Demos - ICT projects in Edinburgh communities}

Eleven pilots were supported by the Demos project in Edinburgh. Four themes were addressed: making the Local Development Committees (LDCs) work better; involving 'hard-to-reach' groups; testing new governance structures, and introducing new information and communication technologies. What follows here is a brief description of Getting Connected, a local project in Edinburgh involving the use of ICTs by senior people living permanently in three residential care homes.

The Getting Connected project developed from a partnership between Edinburgh City Council's Social Work Department, and the Senior Action Group Edinburgh (SAGE), a voluntary organization which helps to ensure a high quality of life for people living in care homes in Edinburgh. The feeling was that older people are generally at risk of social and digital exclusion, with those in care homes even more isolated from mainstream opportunities. A key aim of the Demos Getting Connected project was to highlight the kind of support that would be needed to enable older people in the community to use ICTs to become more actively involved in democratic processes in Edinburgh. A partnership between, SAGE, The City of Edinburgh Council and CityConnect, enabled several care homes in the West district of Edinburgh, to use ICTs to connect to Local Development Council meetings.

SAGE provided the necessary support that enabled residents in care homes to participate and CityConnect provided technological and methodological support as well as equipment, connectivity and staff time. CityConnect is a voluntary organization that promotes lifelong learning in Edinburgh with a particular focus on the use of new technologies that enable wider participation or access to information and learning. The organization seeks to enable socially disadvantaged or excluded groups, individuals or organizations to become aware of the positive benefits that computers and the internet can bring.

The partnership and training by CityConnect provided elderly residents in three homes in the area with a new opportunity to use ICTs to voice their opinions, express their views and receive feedback to questions asked. One-to-one sessions with residents enabled them to raise issues of interest or concern and to receive information about issues that could affect their quality of life. The three homes chosen for the project had up to date computer equipment already installed. The project, which ran from November 2002 until January 2004, also used web-cams, which had already been installed in Local Authority run homes. 
A care worker, volunteers and other staff assisted older people in putting their questions forward. Responses from the city councilors were provided either in real time using ICT or later in writing. The support of volunteers and care staff was crucial in motivating, supporting and maintaining senior citizen interest. A variety of topics for discussion were raised by the participants. While the final Demos evaluation reports are not available at the time of writing, observations of use by CityConnect and care staff are outlined below.

Observations suggest that the elderly people taking part in the project appreciated the visual link with other participating homes and with councilors at their meeting place. Care workers observed that ability to see previously unseen elected councilors by way of a computer link seemed to stimulate senior citizens. In turn, the elderly residents appeared to surprise and impress the councilors with the depth and quality of their questions. City Connect observers noted the participants' pleasure in being able to express their views at an LDC meeting. Participants enjoyed seeing responses from councilors and from participants in other care homes on-screen. This seemed to stimulate debate and conversation. Councilors at the meeting could see the reaction of care home residents to questions and responses and residents in each care home could see each others responses and reactions. This was particularly popular with care home residents.

In addition, care home residents said they felt much more part of the wider community by participating in this way. CityConnect and care home mediators were encouraged by the level of interest shown by care home residents, both in relation to the technology and the opportunity to participate using ICTs. With residents of three homes attending the meetings with the aid of technology, elderly people felt they had a stronger and more powerful collective voice. The text-messaging component was well received and proceedings were typed direct to screens using a very large font size. This allowed people who had poor hearing to get a good idea of what was going on. Moreover, when sound quality diminished, people were still able to follow the progress of the meeting.

On the negative side, CityConnect staff noted that sound quality was not always adequate, mainly because the server had limited bandwidth. It was felt the Committee tended to go through the agenda too quickly. Some confusion arose when slight internet traffic delays combined with confusion over questions or answers. Care home residents sometimes felt frustrated when they believed their questions were not being answered properly. In addition, residents felt they could have had more time to respond to questions. There was also a feeling that Council officials did not answer clearly and tended to overload them with information. The feeling was that clearer and more concise answers to questions would be better received.

In addition, it was felt that more advance information about the agenda could have been made available to the care home residents prior to the meeting, to give them time to consider the issues in more depth. The overall feeling was that, with these new insights, better planning could overcome some of the problems experienced. However, decisions were taken to close down CityConnect in late 2004. Lessons learned may be carried forward to the community grid for learning myEdinburgh (http://www.myedinburgh.org).

\section{Questions of sustainability}

Multiple meanings, controversy and debate now surround the concept of sustainability in relation to ICT and community. The notion of sustainability is associated with the idea of continuity and prolonged life, and is dependent on the extent to which a local electronic network and/or the local community in one way or another can pay for and resource the system beyond the initial external funding period. In Scotland, many community-based technology projects have had short term fixed funding, in reality making it difficult to guarantee long-term survival. A number of seemingly innovative technology developments have been set up in local communities. However, many of these projects are not evaluated in a critical fashion before they disappear. Consequently, problems are not always highlighted and lessons that could help others overcome the same or similar types of problems are not often brought to light.

Where sustainability is built into projects from the beginning, the suggestion is that projects need to outline 'outputs' that others - usually the funders - deem to be sustainable in the long-term. Often, plans for the project to become self-sustaining have to be laid out. This approach suggests an emphasis on generating income to survive. The problem here is that generating income may not be the primary purpose of the project, and leaning too far in this direction may adversely affect the original aims of the project, 
potentially diluting aspirations to support the local community and the public interest. In effect, building the need for sustainability into funding criteria could lead to adverse situations, for example, false expectations and perhaps also frustration at not achieving original goals. An additional temptation may be to pay less attention to highlighting problems and unmet objectives and more to describing successes.

This paper suggests that advance promises of sustainability do not always allow for unforeseen problems and/or unwanted experiences in the course of development. In not working towards sustainability in the expected fashion, however, practitioners may fear adverse implications for themselves and may worry also about not receiving future funding if pre-outlined criteria are unmet. In these circumstances, it is difficult to ensure that the real outcomes of projects are highlighted, critically assessed, and shared. This paper suggests that if funding agencies are inflexible and build need for long-term sustainability into funding criteria, important issues and problems at grassroots levels may not be identified and acknowledged.

A less output-oriented and more far-sighted approach might be to encourage more funding models based on the concept of learning related to meaningful use within a supportive community environment (see Scott \& Page, in Keeble \& Loader, 2001, p. 152-153). This approach draws from an action learning perspective, and places importance on reflections gained from the learning process. Lessons, in other words, are learned in a continuous and iterative fashion. In this approach, projects stay flexible enough to change direction in line with the learning process. Consideration is continuously given to what can be done to improve the learning experience.

The Demos project, discussed above, adopted this approach as they found that participation processes are not always successful. Their report (2004) suggests that "poorly chosen and implemented participation mechanisms can do more harm than good, especially if, for citizens, it is yet another in a long line of poor experiences" (p.19). To be successful, the report suggests, participation processes need to be tailored to local political culture, the administrative and judicial context and the social background of the city or municipality concerned (p. 19). It is vital, in other words, to view participation as a learning process, in which citizens and local authorities proceed by trial and error. Flexibility and ability to adapt and change are central.

In addition, it seems likely that a project's quick arrival into the community and subsequent swift disappearance will have some effect on the people who were informed they would benefit from promised opportunities. Those who have been motivated by locally based opportunities in community networking, only to have their newly formed expectations dashed, are not likely to trust future projects developed along similar lines. The Digital Communities project in Scotland, outlined above, overcame this problem to some extent by permitting local people to keep their computer equipment, albeit without the same level of support or provision of previously free access to the Internet.

It has been argued elsewhere (e.g. Malina \& MacIntosh, 2004), that local technology supported projects to encourage participation need to involve local people, and must be tailored appropriately to local need. Needs assessments are important to tailor development to local needs. In relation to CCIS, the community network discussed earlier in this paper, it might be argued that a 'needs assessment,' collating information from residents, aid groups, and other social and economic organisations in the area, would have helped to include the whole community. Inclusion in designing, developing and using the local network might have generated a greater feeling of community ownership. In turn, support from the whole community could have helped sustain the local network into the future.

Following approaches similar to those outlined in the concept of Community Informatics, Goubin (2004) in the Report and Guidelines from the Demos project ${ }^{10}$ also points to the importance of involving all the stakeholders. Data from one project in Antwerp, for example, suggested that existing resident groups and the local community need to be involved rather than merely involve citizens on an individual basis. While there is no space here to describe them in detail, an interesting series of guidelines to inform participation building are also offered by Goubin in this document.

10 Available at internet site http://www.demosproject.org/admin/files/Demos\%20A4\%20Report_Guidelines.pdf - Retrieved December 2004 


\section{Suggestions for further Research}

As a result of the Scottish Executive policy strategies to support digital inclusion and bridge the Digital Divide, $95 \%$ of people in urban areas in Scotland are now within 1 mile of public internet access, and $90 \%$ of people in rural areas are within 5 miles. ${ }^{11}$ While it may be the focus of future research, research studies in Scotland have not yet explored changes in the nature of interaction and new patterns of networking.

In addition to needs assessments, it would be beneficial now to design research to investigate how different people in different communities in Scotland are beginning to use ICTs in ways that are relevant to their daily lives.

Overall, very little research yet exists in the field to show what people are doing with the technology and how it actually affects their routine lives, their networks of communication, and their local community.

It is noted that OpenScotland now provides an umbrella framework for both the Executive's Modernising Government and Digital Inclusion agendas. The perceived need to re-build community and accumulate social capital has overlapped with the need to ensure everyone is online and skilled enough to receive electronic public services by 2005 .

The concept of a 'digital divide' has provided the basis for ensuring everyone is on-line to participate in different ways in the Information Society. Communities are viewed as very important because they provide the foundation for technology and local networks of relations to develop. As Table 2 indicates, however, different types of e-participation associated with different societal roles being developed for the technology suggest different types of involvement at community level (Malina, 2003).

\begin{tabular}{|l|l|}
\hline \multicolumn{2}{|c|}{ Table 2. ICTs and different kinds of e-participation } \\
\hline Contexts & Primary defining features of new roles for ICTs \\
\hline e-government & $\begin{array}{l}\text { Design of new roles for ICTs to support more meaningful interaction } \\
\text { between citizens, representatives and government, including citizen } \\
\text { participation in politics and service delivery; also the application of } \\
\text { ICT and e-business techniques to the machinery of government, to } \\
\text { support cheaper, faster, more efficient and more effective e- } \\
\text { administration processes }\end{array}$ \\
\hline e-governance & $\begin{array}{l}\text { New roles for ICT to broaden horizontal input to government policy- } \\
\text { making processes }\end{array}$ \\
\hline e-democracy & $\begin{array}{l}\text { New roles for ICTs to support two-way information flow, e- } \\
\text { participation and e-voting. Increased use of 'your say' type provision, } \\
\text { and introduction of e-consultation and e-deliberation methods at local } \\
\text { level to support citizen input to policy-making and democratic } \\
\text { decision-making processes }\end{array}$ \\
\hline e-community networking & $\begin{array}{l}\text { Electronic interaction organized by and for communities to address } \\
\text { local and public interest issues in electronic networks and public } \\
\text { spheres that remain separate from government and market control }\end{array}$ \\
\hline digital inclusion technology & $\begin{array}{l}\text { Funding and support for locally based technology projects to bridge the } \\
\text { 'digital divide' and ensure wider access to contemporary ICTs. Key } \\
\text { aspirations are to include excluded communities and broaden skills to } \\
\text { use ICTs to participate in social, cultural, political and economic } \\
\text { aspects of the Information Society }\end{array}$ \\
\hline Source: Adapted from Malina, 2003.
\end{tabular}

One problem is that the significance of these different kinds of e-participation in different types of communities is not yet fully known. Malina (2003) suggests need for more empirical research to evaluate how different types of e-participation are perceived and practiced in diverse communities.

11 http://www.scotland.gov.uk/about/FCSD/21stCG/00017820/page737676964.aspx Retrieved July 2004. 
Action research provides an appropriate approach to support greater participation and broaden understanding of different conditions and diverse needs. Malina \& MacIntosh (2004), suggest that:

While much interest surrounds the concept of improving democratic participation using technology, e-participation in a civic and political sense is a relatively new policy and practice area. What are needed are action research studies to examine requirements of e-participation in diverse local communities. Findings from such studies would provide input into policy planning. In conducting action research and analyzing empirical evidence gathered at the grassroots level, studies of this type would indicate the ways in which technology could be designed to support e-democracy and civic participation suited to different needs. (p.269)

A very different problem is that technology's ability to promote social development and build social capital is sometimes overemphasised. Without complimentary resources and continuous interventionist policies, technology alone could not build social capital or support social inclusion.

Assumptions that new technologies set up in local communities - often without consultation with or input by local people - will have positive outcomes for the community must be questioned. This paper suggests need for more empirical research to indicate how and in what ways different types of communities are utilising ICTs and what implications this use has in reality for routine daily living.

Understanding of the patterns of relationships and interrelationships developing between ICTs and community are indistinct. Social Network Analysis would help identify patterns in people's on and off-line interaction, identifying also how and in what ways relationships and inter-relationships might be strengthened through electronic interaction. The ways in which new technology is affecting social networks and social capital are also rich arenas for future research.

Action Research combined with Social Network Analysis would be very helpful in indicating how use of new technology in different communities may be affecting social, cultural, political, and economic relationships with others inside and outside the local area. Evidence based information would help to build cohesive and collaborative relationships between different partners at regional and local levels, and might help also to structure and support future community networking practice in diverse communities.

\section{Conclusion}

The analysis of CCIS Edinburgh reported in this paper suggests it is important to ensure on-line interaction between partners is based on mutual trust in the real world. More rigorously conducted critical evaluations of projects throughout Scotland might help to ensure that benefits and problems are highlighted. Better understanding of the possibilities and limitations of ICTs in local communities may be helpful in formulating future policies.

Networked collaborations and partnerships will increase opportunity for academic researchers to become involved in strategies for ICT and community.

There is great potential now to investigate aspects of e-government, e-governance, e-democracy, and health informatics, assessing the implications of different types of e-participation for different communities. Each thematic area provides a rich arena for in-depth survey work, action research and critical analysis.

There is potential for communities to become actively involved in increasing equity of service through improved communications infrastructure and better access and use of government health services, education, training, and many other electronic services delivered to people in their communities.

New possibilities are emerging for people to become involved in on-line political discussions and democratic decision-making. Much can be learned from explorations of institutional, contextual and technological problems and barriers to the viability of increasing democratic participation from the bottom up. Rich data from research would help to further understanding of the possibilities offered and difficulties encountered in enabling more active and responsive communities.

The extent to which ICTs are empowering local people to generate social, cultural, political and economic outcomes needs to be more rigorously investigated to further understanding of the relationship between community development and community empowerment. 
Similar to other countries in the world, the community and voluntary sector in Scotland have been placed at the centre of developing ICTs in the community, often to support welfare provision. There is much scope for community informatics researchers to work with groups to assess different requirements and design technology suited to specific needs in diverse local communities.

To finalise, it would be extremely useful to critically assess transformations in local communities, identify and air problems and learn lessons from others, and also to build on best practice and disseminate information at local levels as well as within academic surroundings. Combining action research with a social learning approach and flexible organisation involving a variety of partners might help support more sustainable development of ICT in local geographic communities. 


\section{References}

Argyll and Bute Council First Round Digital Communities Submission, 2002. Argyll \& Bute Council.

Bajjaly, S. (1999). The Community Networking Handbook. USA: ALA Editions.

Bellsmyre, West Dunbartonshire First Round Digital Communities Proposal, 2002. West Dunbartonshire Council.

Castells, M. (1996). The Rise of the Network Society. London: Blackwell Publishers Ltd.

Citizens Innovation Local Governance: A 21st Century Approach. Demos Project Edinburgh Conference 2004. Report \& Guidelines from the Demos Project.

Cohill, A. \& Kavanaugh, A. (eds). (2000). Community Networks: Lessons from Blacksburg, Virginia. USA: Artech House.

Digital Communities Final Report (2004). DTZ Pieda.

Digital Inclusion Audit: Public Internet Access in Social Inclusion Partnership Areas. (2004) Scottish Enterprise.

Gaventa, J. \& Blauert, J. (1999). Learning to Change by Learning from Change: Going to Scale with Participatory Monitoring and Evaluation. In Estrella, M., et al (eds), Learning from Change: Issues and Experiences in Participatory Monitoring and Evaluation, London: IT Publications.

Giddens, A. (1998a, May 1). 'After the Left's paralysis'. New Statesman, 1st May 1998. pp.18-21.

Giddens, A. (1998b). The Third Way: The Renewal of Social Democracy, Cambridge: Polity Press.

Goubin, E. (n.d.). Participation Methods: How to think about getting started. In Citizens Innovation Local Governance: A 21st Century Approach. Demos Project Edinburgh Conference 2004. Report \& Guidelines from the Demos Project.

Gurstein, M. (n.d.). Third International Workshop on (Virtual) Community Informatics: Electronic Support for Communities - Local, Virtual and Communities of Practice. Paper retrieved July 2004 from http://www.is.njit.edu/vci-www2003/

Hampton, K. (1999). Living the Wired Life in the Wired Suburb: Netville, Glocalization and Civic Society. Doctoral Dissertation, Department of Sociology. University of Toronto.

Keeble, L. \& Loader, B. (2001). Community Informatics: Shaping Computer-mediated Relations. London $\&$ New York: Routledge.

Kretzman, J.P. \& McNight, J.L. (1993). (eds). Building Communities from the Inside Out. Chicago: ACTA Publications.

Loader, B. \& Keeble, L. Challenging the digital divide?: A literature review of Community Informatics initiatives. UK: The Joseph Rowntree Foundation. Retrieved May 10, 2005 from: http://www.jrf.org.uk/knowledge/findings/socialpolicy/584.asp.

Malina, A. (2001). Electronic Community Networks: Community development practice, e-democracy and community learning. Journal of Community Work and Development, 1:2.

Malina, A. (2002). Community Networking and Perceptions of Civic Value. In Communications 27, 211 234.

Malina, A. \& MacIntosh, A. (2004). Bridging the Digital Divide - Development in Scotland. In Ari-Veikko Anttiroiko \& Matti Mälkiä \& Reijo Savolainen, (eds). eTransformation in Governance: New Directions in Government and Politics. Idea Group Publishing (IGP).

Pantry, S. (Ed.). (1999). Building Community Information Networks: Strategies and Experiences. London: Library Association. 
Putnam, R.D. (2000). Bowling Alone: the collapse and revival of American Community. NY: Simon \& Schuster.

Quan-Haase, A. \& Wellman, B. (2002). How does the Internet affect Social Capital? In Huysman, M. \& Wulf V. (Eds.), IT and Social Capital, Cambridge: MIT Press.

Quan-Haase, A., Wellman, B., with Witte, J., \& Hampton, K. (2002). Capitalizing on the Internet: Social contact, civic engagement, and sense of community. In B. Wellman \& C. Haythornthwaite (Eds.). Internet and everyday life. London, UK: Blackwell.

Reddick, A. (2002) Tracking the dual digital divide. Canada: EKOS Research Associates Inc.

Resnick, P. (2001). Beyond Bowling Together: SocioTechnical Capital. Retrieved July 2004 from: http://www.si.umich.edu/ presnick/papers/stk/ResnickSTK.pdf

Schuler, D \& Namioka, A. (1993). (eds). Participatory design: Principles and practices. Hillsdale, NJ: Lawrence Erlbaum Association.

Page, M. and A. Scott, (2001). Change Agency and Women's Learning: New practices in community informatics. In Keeble, L. \& Loader, B. (Eds), Community Informatics: Shaping Computermediated Relations. London \& New York: Routledge.

Schmitz, J. (1997). Structural Relations, Electronic Media, and Social Change: The Public Electronic Network and the Homeless. In Jones, S. (Ed), Virtual culture: Identity and communication (pp. 80 - 101). London: Sage.

Scottish Executive (2001) Connecting Scotland: Our Broadband Future. A Scottish Executive publication.

Scottish Executive (2001) Digital Inclusion: Connecting Scotland's People. A Scottish Executive publication. Retrieved July 2004 from: http://www.scotland.gov.uk/library3/enterprise/dics00.asp.

Scottish Executive (2000) Digital Scotland Task Force Report. A Scottish Executive publication, also published at: http://www.scotland.gov.uk/digialscotland/digital scotland.pdf.

Scottish Enterprise. (2004) Digital Inclusion Audit. Digital Inclusion Champions. Retrieved July, 2004 from: http://www.ltscotland.org.uk/communities/digitalinclusion/audit.asp

Scottish Executive. (2004) Evaluation of the Public Internet Access Point Initiative. Hall Aitken.

Spectrum MIT. (2004) Internet Connection: Being Wired Encourages Human Contact. Retrieved from http://web.mit.edu/giving/spectrum/spring04/internet-connection.html

Wellman, B. (1999). The Network Community. In B. Wellman (Ed.), Networks in the global village (pp. 148). Boulder, CO: Westview.

Tsagarousianou, R., Tambini, D., \& Bryan, C. (Eds). (1998). Cyberdemocracy: Technology, Cities and Civic Networks. London \& New York: Routledge.

Wellman, B. Quan-Haase, A. Boase, J. and Chen, W. Examining the Internet in Everyday Life. Keynote address (given by Barry Wellman) to the Euricom Conference on e-Democracy, Nijmegen, Netherlands, October 2002. Retrieved from the Internet July 2004 at: http://www.chass.utoronto.ca/ wellman/publications/euricom/Examinig-Euricom.htm

Wilhem, Anthony. (2000) Democracy in the digital age: Challenges to political life in cyberspace. New York and London: Routledge. 